\title{
An outbreak of diphtheria in a hospital for the mentally subnormal
}

\author{
G. S. ANDERSON AND J. B. PENFOLD \\ From the Pathology Department, Essex County Hospital, Colchester
}

SYNOPSIS An account is given of two separate outbreaks of diphtheria amongst mentally subnormal patients and nursing staff. In a total hospital population of about 1000 the number of people involved as carriers or cases was 60 and there were five deaths. The 60 people comprised 56 patients, of whom four were involved in both outbreaks, and four nurses. The organisms isolated were $C$. diphtheriae mitis but five strains were non-toxigenic. It is postulated that the outbreak began following the conversion of a non-toxigenic organism to a toxigenic one by bacteriophage action. The fatal cases were examples of membranous pharyngo-laryngo-tracheo-bronchial diphtheria with well marked pseudo-casts of the upper air passages.

No apology is necessary today in reporting an outbreak of diphtheria in this country. It is difficult to realize that in 1940 , the year the Government decided on its massive immunization policy, more than 45000 cases were notified in England and Wales with nearly 2500 deaths, mostly in school children. Today diphtheria is rare, but it remains a dangerous and deadly disease.

Received for publication 12 June 1973.

\section{Epidemiology}

THE HOSPITAL

The epidemic occurred in Turner village which is part of the Royal Eastern Counties Hospital complex on the outskirts of Colchester. In it live 600 mentally subnormal patients and there are about 140 nurses together with 250 other staff, a total population of about 1000 . Although the patients are not of the

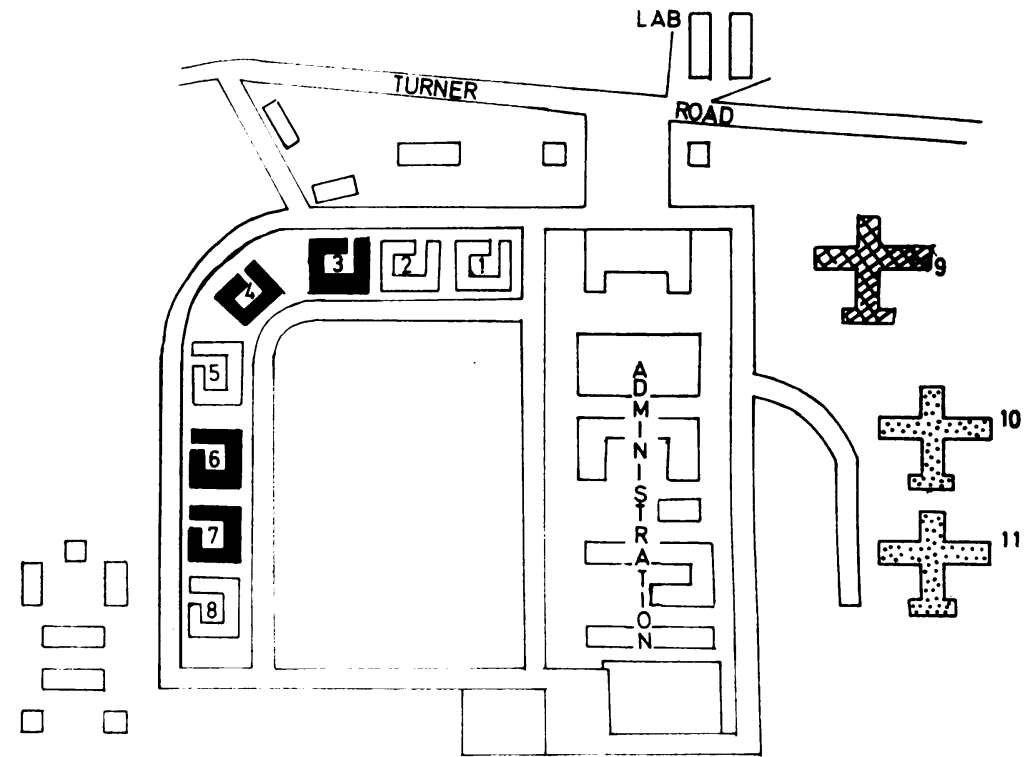

Fig 1 Plan of Turner village showing the villas affected in both outbreaks in black and in the second outbreak stippled. Villa 9 (hatched) had a nurse harbouring a non-toxic strain in the first outbreak. 
lowest grade, they are severely subnormal and often quite untrainable in ordinary hygiene.

In Turner village are 11 villas, housing up to 60 patients in a villa, together with the usual administrative, therapeutic, recreational, and other buildings (fig 1). Patients of the same sex are allowed to mix for recreational and occupational activities. All the patients are male except those in villa 8 , and the children are housed in villa 9 . The plan and bed arrangement are the same for villas 1 to 8 with a separate arrangement common to villas 9,10 , and 11 . There is a serious state of overcrowding, readily seen in the plans. Not only is there a shortage of beds but the nursing staff is about a third under establishment. Although the majority are British born, quite a number of nurses come from overseas, particularly Mauritius, and the manner in which they nurse difficult and uncooperative patients is impressive. The senior nursing staff are well trained and well versed in the leadership of their staff and in handling of their difficult patients. The patients are looked after by the consultant psychiatrists and their assistants and they can call on the help of a local group of general practitioners in the case of physical disease.

The diagnosis of disease of any kind in these patients is difficult. Many patients are unable to talk or to understand simple commands or questions and many show little or no signs of disease until the terminal stages or even death has occurred.

\section{THE FIRST EPIDEMIC}

On 5 May 1970 a male patient aged 23 in villa 3 had a fulminating illness diagnosed as bronchopneumonia. He died on 6 May after an illness of 25 hours and at necropsy on 8 May an extensive membrane covered the fauces, trachea, and bronchi. Cultures for diphtheria bacilli from pharyngeal and bronchial swabs proved negative and the case was termed acute pharyngo-tracheo-bronchitis.

On 24 May (18 days later) a male patient aged 48 in villa 6 died after a nine-hour illness with bronchopneumonic symptoms. No suspicions were aroused that this patient had an unusual form of pneumonia and no swabs were taken nor was a necropsy done.

On 28 May three patients in villa 6 fell ill with sore throat, dyspnoea, and temperature of $100^{\circ} \mathrm{F}$ $\left(37 \cdot 8^{\circ} \mathrm{C}\right)$. They had visible membranes on the throat and typical $C$. diphtheriae mitis was isolated from swabs. They were diagnosed clinically as diphtheria by a young general practitioner who had never seen a case before. They were transferred to the Isolation Hospital on the same day and treated with erythromycin, but one (a man of 43) died on 30 May. The necropsy was done on 31 May. Also in villa 6 another man fell ill on 31 May and died that day and a necropsy was done on 1 June.

By this time full-scale throat and nose swabbing was being undertaken, staff transfer and visiting patients were prohibited, villas isolated, and benzathine penicillin and phenoxymethyl penicillin were given to all patients in the affected villas. Immunization with two doses of TAF of all patients and staff in the village was begun and Schick tests were carried out on staff and patients. Of 619 patients tested, $73(12 \%)$ were positive and 45 staff $(13 \%)$ were positive out of 350 .

On the first routine swabbing, positive throat and nose swabs were obtained from an asymptomatic patient, a man aged 21 in villa 3 where the presumptive first case had occurred almost a month before without intervening cases.

Between 2 and 7 June, 12 more positive swabs were obtained from patients, usually from the throat, sometimes from the nose and throat, and once from the nose only. One of these patients was in villa 3 , one in villa 4 , three in villa 6 , and seven in villa 7 . They were asymptomatic except two in villa 7 with mild symptoms. The organism from one of the patients in villa 6 was avirulent.

Six days later a positive swab was obtained from an asymptomatic Mauritian nurse in the children's villa (villa 9). While typical in all other ways it was shown to be avirulent and non-toxigenic. A similar organism was obtained from a female Indian nurse working with the cases in the Isolation Hospital.

Routine swabbing continued in Turner village and three weeks later on 28 June three more carriers were found in villa 6 , this proving to be the end of the first epidemic. In all 22 patients and two nurses were involved, with four deaths, four others with symptoms, and 14 asymptomatic among the patients. The two nurses were asymptomatic and with avirulent organisms. Three negative nose and throat swabs were obtained from all patients and staff only after which the epidemic was considered over.

\section{THE SECOND EPIDEMIC}

Five months later on 23 November, a male patient aged 23 in villa 7 was noticed to have a high temperature and rapid respiration. He was the only patient in the whole village not immunized at the time of the first outbreak. A clinical diagnosis of diphtheria was made, a throat and nose swab taken, and he was transferred immediately to the Isolation Hospital where he died the next day. On 25 November at necropsy diphtheria bacilli were isolated from the nose and throat swabs taken initially and from those taken after death from pharynx, trachea, and bronchi.

All precautions were set up again and three nose 


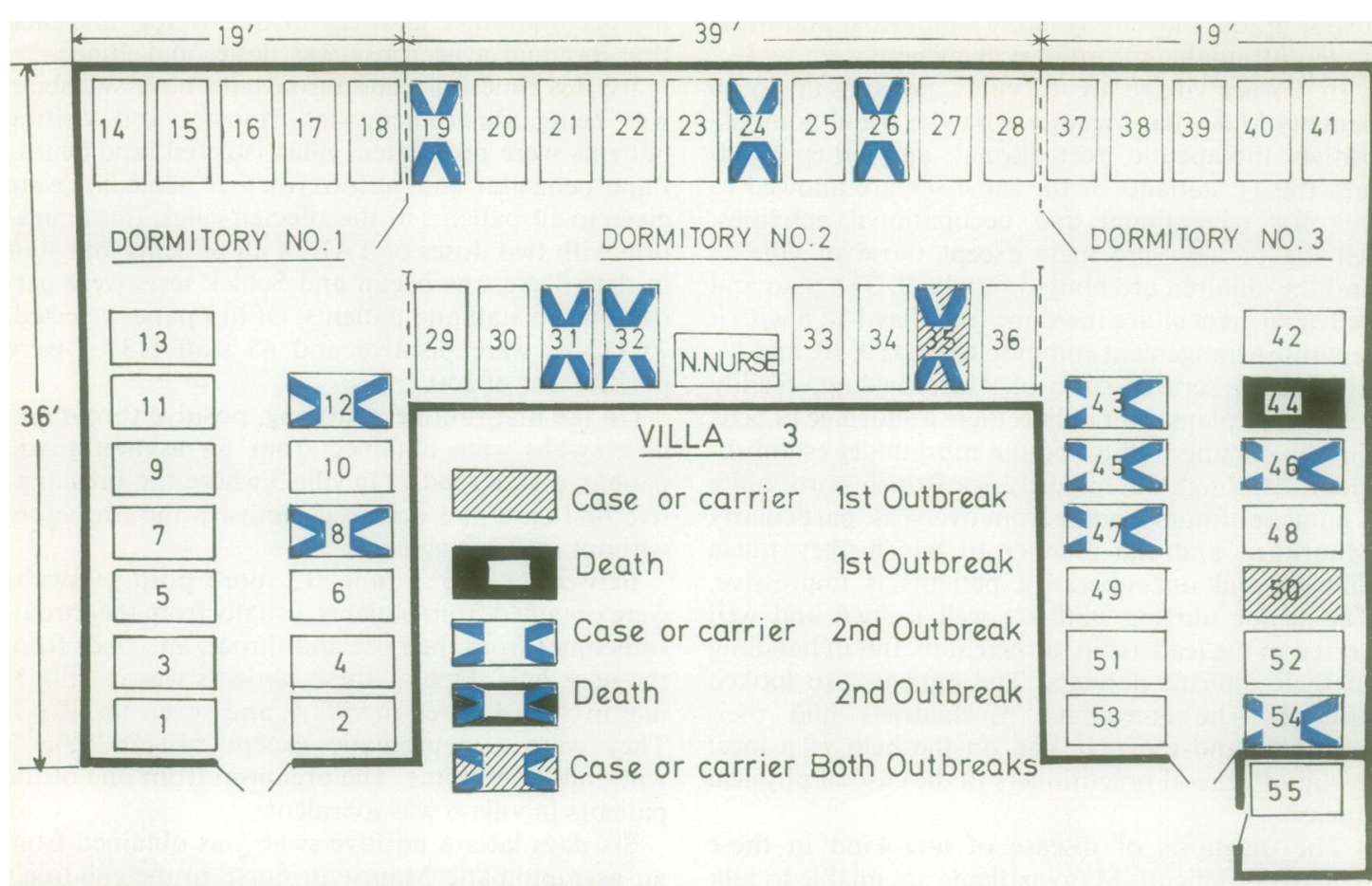

Fig 2 Distribution of cases and carriers in villa 3.

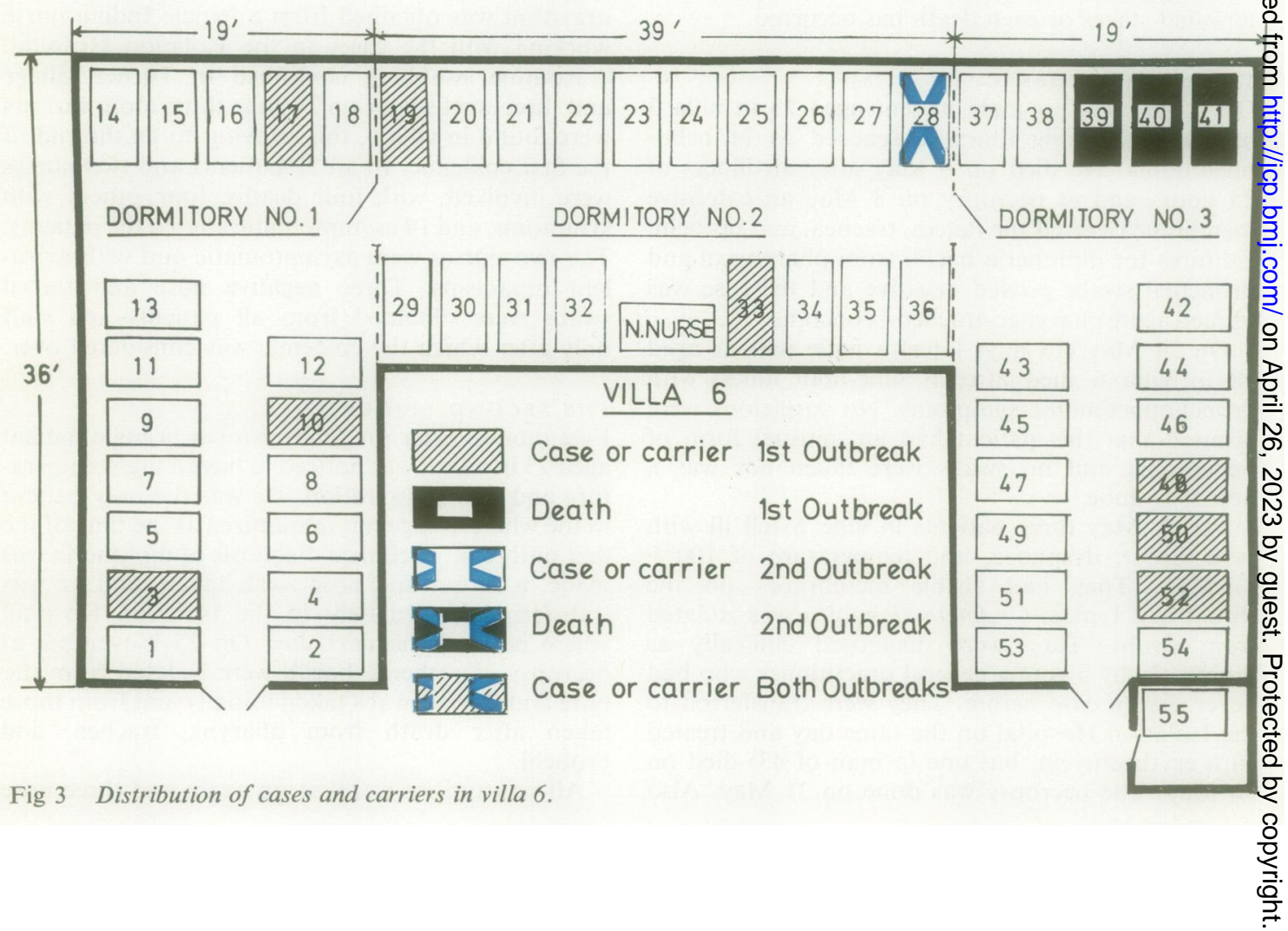




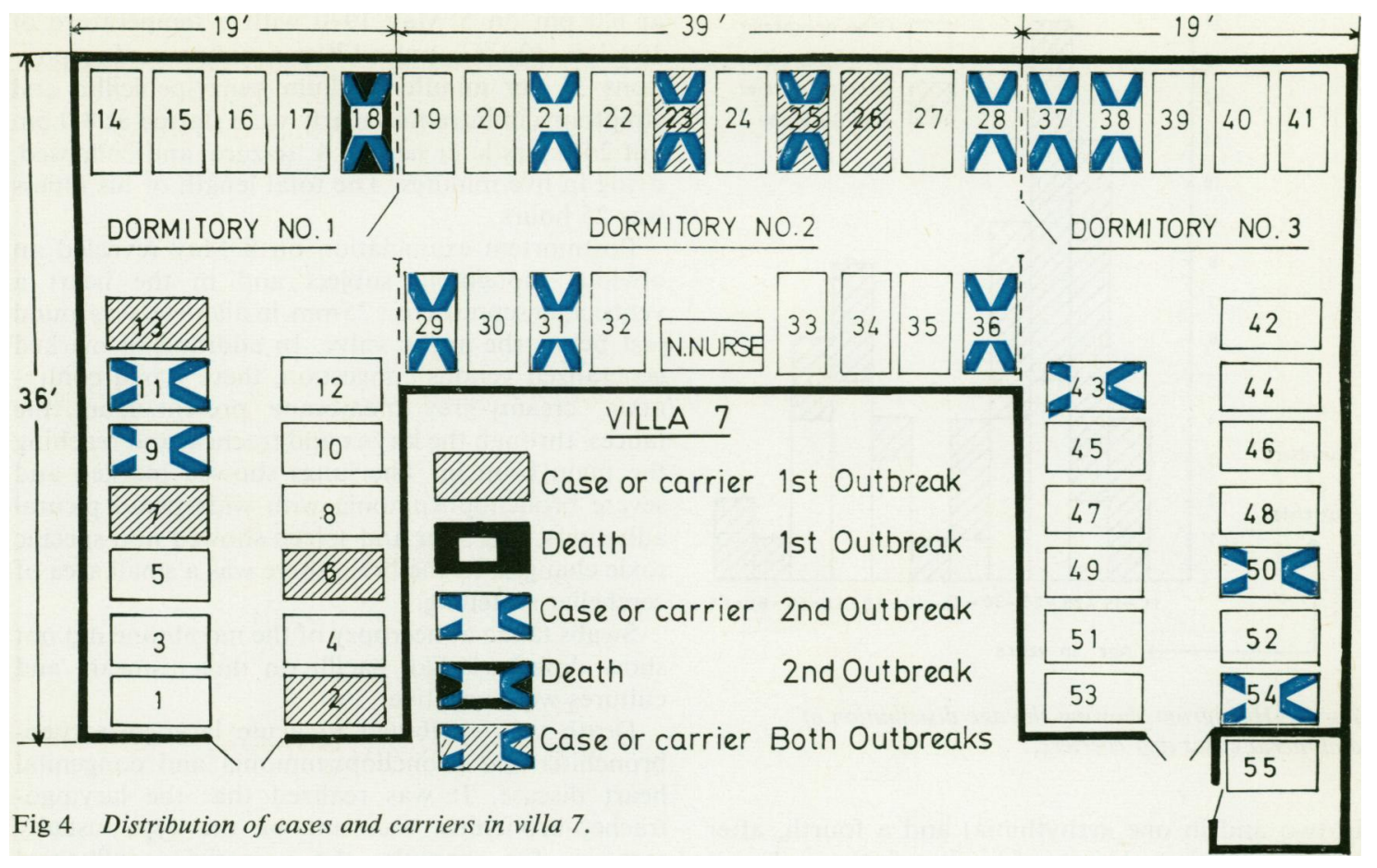

\begin{tabular}{|c|c|c|c|c|c|c|c|c|c|c|c|}
\hline \multirow[t]{2}{*}{ Distribution } & \multicolumn{5}{|c|}{ First Outbreak } & \multicolumn{5}{|c|}{ Second Outbreak } & \multirow{2}{*}{$\begin{array}{c}\text { Total Both } \\
\text { Outbreaks }\end{array}$} \\
\hline & Deaths & $\begin{array}{l}\text { Surviving } \\
\text { Cases }\end{array}$ & $\begin{array}{l}\text { Carriers of } \\
\text { Toxigenic } \\
\text { Bacteria }\end{array}$ & $\begin{array}{l}\text { Carriers of } \\
\text { Non- } \\
\text { toxigenic } \\
\text { Bacteria }\end{array}$ & Total & Deaths & $\begin{array}{l}\text { Surviving } \\
\text { Cases }\end{array}$ & $\begin{array}{l}\text { Carriers of } \\
\text { Toxigenic } \\
\text { Bacteria }\end{array}$ & $\begin{array}{l}\text { Carriers of } \\
\text { Non- } \\
\text { toxigenic } \\
\text { Bacteria }\end{array}$ & Total & \\
\hline $\begin{array}{l}\text { Villa } 3 \\
\text { Villa } 4 \\
\text { Villa } 6 \\
\text { Villa } 7 \\
\text { Villa } 10 \\
\text { Villa } 11 \\
\text { Nurses }\end{array}$ & $\begin{array}{l}1 \\
0 \\
3 \\
0 \\
0 \\
0 \\
0\end{array}$ & $\begin{array}{l}0 \\
0 \\
2 \\
2 \\
0 \\
0 \\
0\end{array}$ & $\begin{array}{l}2 \\
1 \\
5 \\
5 \\
0 \\
0 \\
0\end{array}$ & $\begin{array}{l}0 \\
0 \\
1 \\
0 \\
0 \\
0 \\
2\end{array}$ & $\begin{array}{r}3 \\
1 \\
11 \\
7 \\
0 \\
0 \\
2\end{array}$ & $\begin{array}{l}0 \\
0 \\
0 \\
1 \\
0 \\
0 \\
0\end{array}$ & $\begin{array}{l}5 \\
1 \\
0 \\
3 \\
1 \\
0 \\
0\end{array}$ & $\begin{array}{r}7 \\
3 \\
1 \\
11 \\
2 \\
2 \\
1\end{array}$ & $\begin{array}{l}1 \\
0 \\
0 \\
0 \\
0 \\
0 \\
1\end{array}$ & $\begin{array}{r}13 \\
4 \\
1 \\
15 \\
3 \\
2 \\
2\end{array}$ & $\begin{array}{r}16 \\
5 \\
12 \\
22 \\
3 \\
2 \\
4\end{array}$ \\
\hline Total & 4 & 4 & 13 & 3 & 24 & 1 & 10 & 27 & 2 & 40 & $64^{1}$ \\
\hline
\end{tabular}

Table I Summary of the two outbreaks

'Four of these were repeat carriers, one in villa 3, one in villa 6 (with avirulent organisms in the first oubreak and virulent in the second; he also moved his bed between the outbreaks) and two in villa 7 . The total number of persons involved was therefore 60.

and throat swabs were taken from every patient and member of staff within a fortnight. Four laboratories collaborated in the mammoth task of dealing with 5000-6000 swabs in two weeks. Amongst the patients the following distribution of positive swabs revealed 13 affected men in villa 3 (five with mild nasal discharge and one asymptomatic harbouring a non-toxigenic bacillus), three in villa 4 (one with mild symptoms and two without), an asymptomatic carrier in villa 6,14 in villa 7 (three with mild symptoms), two in villa 10 (one with mild symptoms) and two asymptomatic carriers in villa 11 . Four were repeat carriers from the first outbreak, one in villa 3 , two in villa 7 , and one in villa 6 whose organism, although now virulent, had been avirulent in the first outbreak. In addition two asymptomatic nurse carriers were found amongst the staff, one with a non-toxigenic strain giving up to then a total of 38 in the second outbreakincluding the fatal case. Three of the 10 patients with mild upper respiratory symptoms without membrane developed cardiac lesions (tachycardia 


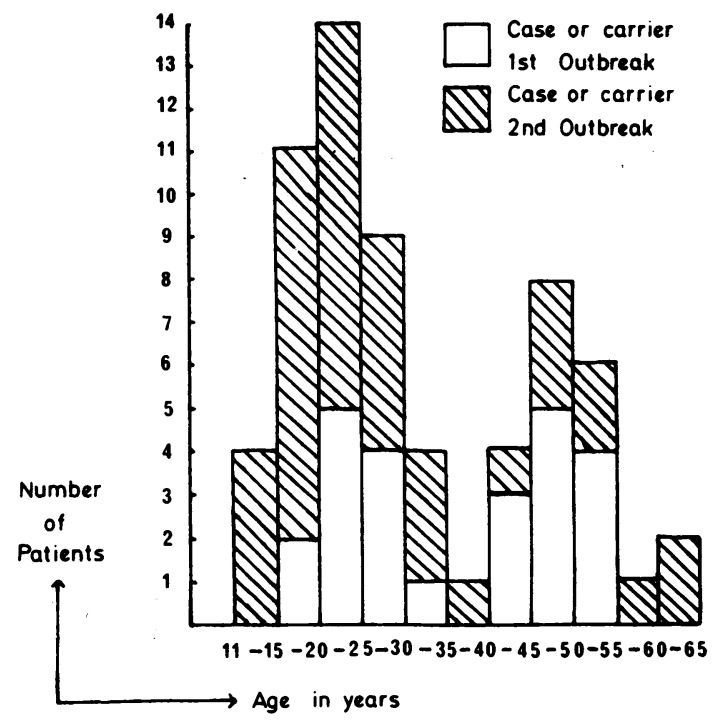

Fig 5 Histogram showing the age distribution of diphtheria cases and carriers.

in two and in one arrhythmia) and a fourth, after three weeks, lost the use of his legs for a week and then recovered.

It was decided to swab all patients and staff of the village every month for six months and the second of these swabbings produced one further carrier in villa 4. All other swabbings on patients, fomites, furnishings, and fittings, etc, were negative until on 12 March 1971 a positive throat swab was obtained from a chairbound 53-year-old patient in villa 10. He had been immunized in June 1970 and his Schick test was negative in December 1970. He had had eight successive negative swabs during and after the outbreaks.

Table I sets out the distribution of deaths, cases, and carriers in both outbreaks, and figures 2, 3, and 4 show the positions of the beds occupied by patients who died and who were cases or carriers in both outbreaks. Figure 5 shows two distinct age peaks.

\section{Morbid Anatomy and Histology}

THE FATAL CASES

\section{Case 1}

This was a male patient aged 23 , suffering from Down's syndrome, unable to speak, feed, wash, or dress himself, and doubly incontinent. There was a past history of frequent infections including bronchopneumonia in 1962,1965, and 1969, which responded to antibiotics. He was noticed to be ill at $6.0 \mathrm{pm}$ on 5 May 1970 with a temperature of $104 \cdot 2^{\circ} \mathrm{F}\left(40 \cdot 1^{\circ} \mathrm{C}\right)$, pulse 120 per minute, and respirations 35 per minute. Sodium benzylpenicillin and streptomycin intramuscularly were started at $8.0 \mathrm{pmo}$ but 24 hours later he had a 'seizure' and collapsed, dying in five minutes. The total length of his illness $\frac{\bar{c}}{\sigma}$ was 25 hours.

Postmortem examination on 8 May revealed an obvious mongoloid subject and in the heart $a^{\mathrm{c}}$ ventricular septal defect $25 \mathrm{~mm}$. in diameter was found $\odot$ just below the aortic valve. In addition to marked $\vec{\omega}$ generalized venous congestion, there was a contin- $\omega$ uous, creamy-grey membrane present from the fauces, through the larynx and trachea, and reachingi the main bronchi. The lungs showed marked and severe bronchopneumonia with widespread pleural $\%$ adhesions. The liver and spleen showed non-specific $\odot$ toxic changes. In the brain there was a small area of $\frac{}{\square}$ cerebellar softening.

Swabs taken at necropsy of the membrane did not $\gg$ show diphtheria-like bacilli on direct smears andec cultures were negative.

Death was attributed to acute laryngo-tracheo- $\vec{\varphi}$ bronchitis and bronchopneumonia and congenital heart disease. It was realized that the laryingotracheo-bronchitis was not of the type usually seen in, for example, the necrotizing influenzal pneumonia. From experience of later cases we are in no doubt that this patient died of diphtheria with $\frac{\emptyset}{\not}$ secondary pyogenic infection.

\section{Case 2}

This patient is presumed to have died from diphtheria but a postmortem examination was not requested.

The patient was a male aged 47, with Down's syndrome, who spoke only a few words and required? help in feeding, washing, and dressing. At times he $\frac{}{3}$. was doubly incontinent and there was a past history of infections of the lungs, eyes, and skin, all responding to appropriate treatment.

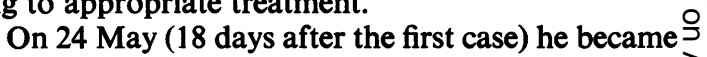
ill at 10.0 am with a temperature of $100^{\circ} \mathrm{F}\left(37 \cdot 8^{\circ} \mathrm{C}\right)$, $\frac{D}{0}$ pulse 110 per minute, and respirations of 23 per minute. He was described as 'chesty' and sodium $N$ benzylpenicillin and streptomycin were started ${ }_{N}$ immediately. His condition was unchanged for the rest of that day but at $6.45 \mathrm{pm}$ there was a rapid ${ }^{\omega}$ deterioration and he died at $7.15 \mathrm{pm}$. The total length of illness was nine hours. Death was attributed to bronchopneumonia and in the absence of $\mathrm{a} \stackrel{\oplus}{\Phi}$ necropsy we can only suspect diphtheria.

\section{Case 3}

This male patient aged 43, with Down's syndrome, $\frac{\stackrel{\rho}{\oplus}}{\Phi}$ could talk a little and was able to dress and feed $\mathbb{Q}$ himself. At times he was doubly incontinent. There 
was a past history of infections of the skin, eyes, and ears, and in 1969 he had bronchopneumonia and influenza responding to antibiotics.

He became ill on 28 May (four days after case 2) with a temperature of $100.4^{\circ} \mathrm{F}\left(38.0^{\circ} \mathrm{C}\right)$, pulse 125 per minute, and wheezy respirations of 40 per minute. Oxytetracycline was immediately started but he did not improve and 24 hours later he was cyanosed with bronchospasm. His throat was not clearly seen but some greyish-yellow fluid was glimpsed and the tonsils were red. At this stage he was transferred to the Isolation Hospital and a throat swab taken with difficulty. His condition deteriorated and he died the next day after an illness of 36 hours. As the clinical suspicions of diphtheria were strong in this case a necropsy was carried out within a few hours of death.

At postmortem examination the patient was a short, stocky mongol. In addition to marked oedema

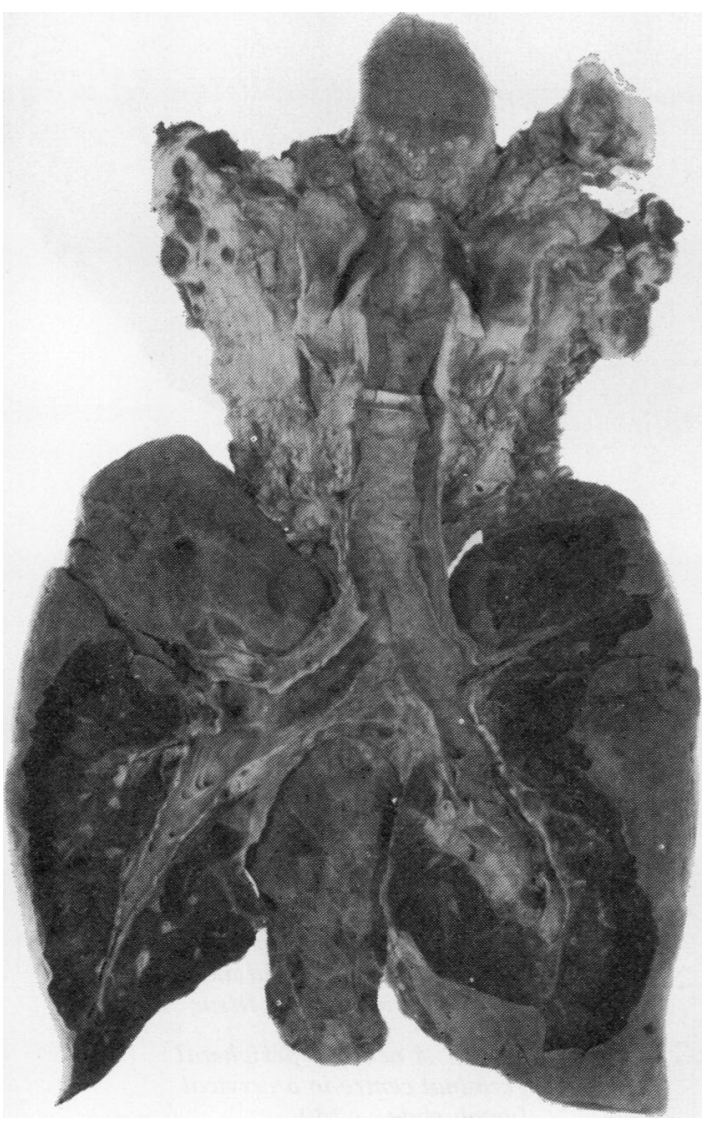

Fig 7 Case 3, showing the continuous membrane from the larynx to the bronchioles and oedema of the soft tissues of the neck. of the glottis and congested and swollen cervical lymph nodes and tissues there was a greyish-yellow membrane present over the tonsils which extended in continuity down the larynx, trachea, and bronchi merging in the bronchioles with obvious pus (fig 6). Over the base of the tongue and tonsils the membrane appeared dry and tough but in the trachea and bronchi it was more easily detached. The lungs showed foci of bronchopneumonia.

Other positive findings were a membranous upper ventricular septum in the heart, a small spleen with a soft pinkish-grey pulp, undescended testicles, and a small area of cortical softening on the under surface of the right temporal lobe. Swabs from the membrane yielded morphological diphtheria bacilli which on further investigation were shown to be virulent and toxigenic $C$. diphtheriae mitis.

Histology showed a membranous tonsillitis and tracheitis and suppurative bronchopneumonia

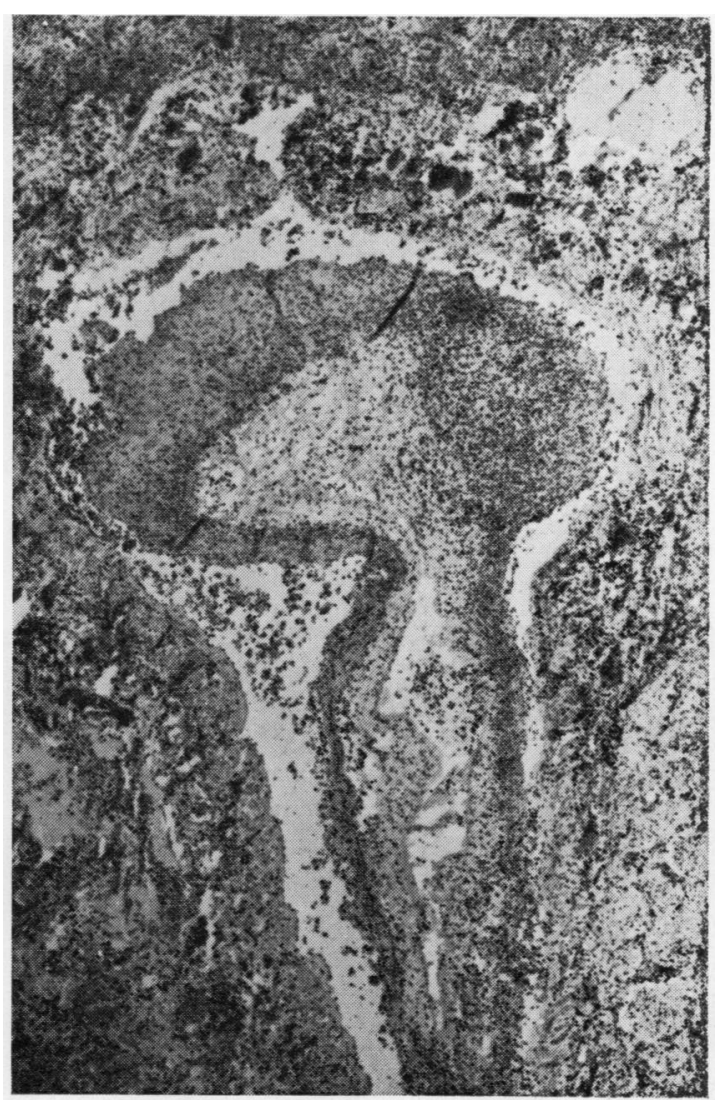

Fig 8 Diphtheritic membrane and suppurative inflammation in a small bronchiole. $\times 25$. 

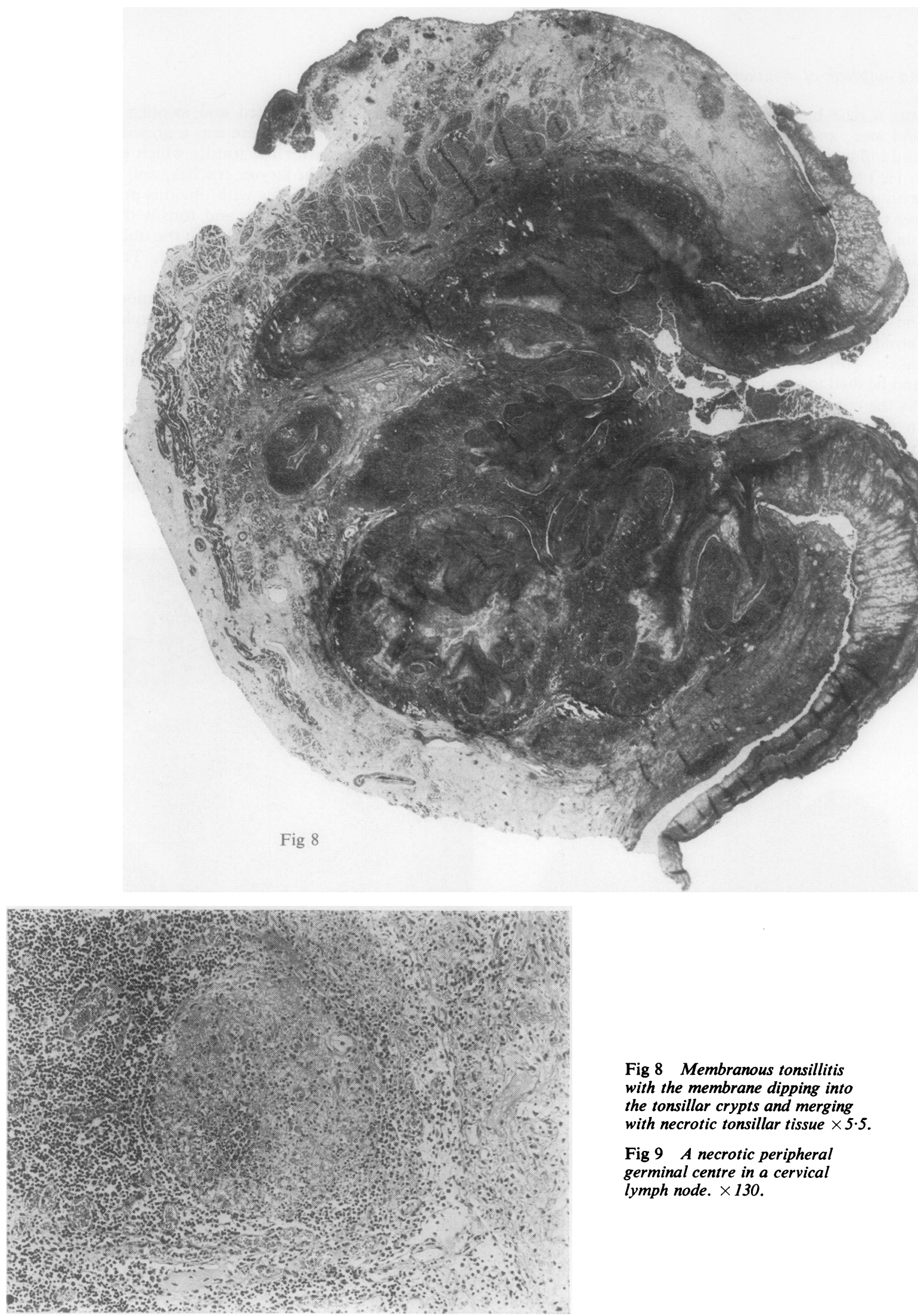

Fig 8 Membranous tonsillitis with the membrane dipping into the tonsillar crypts and merging with necrotic tonsillar tissue $\times 5 \cdot 5$.

Fig 9 A necrotic peripheral germinal centre in a cervical lymph node. $\times 130$. 
but no convincing diphtheritic organisms were seen in Gram-stained sections (figs 7 and 8). Sections of the cervical lymph nodes, however, revealed characteristic necrotizing lesions of the germinal centres of the lymphoid follicles (fig 9) in addition to congestion and oedema in the nodes and surrounding tissues. No specific histological changes were found in heart muscle, nervous tissue, or other organs.

\section{Case 4}

This was a severely subnormal deaf and dumb male of 49 needing constant attention. In contrast to the other cases his general health had been good. On 29 May a throat swab was taken but no $C$. diphtheriae was isolated. On 31 May (seven days after case 3) at 10.0 am he became ill with a temperature of $102 \cdot 2^{\circ} \mathrm{F} .\left(39.0^{\circ} \mathrm{C}\right)$, pulse 134 per minute, and respirations of 34 per minute. His throat was parched with an adherent membrane on the left side with the impression of an underlying pharyngeal abscess. In addition there was a conjunctivitis and a nasal discharge. Before $7.0 \mathrm{pm}$, when he collapsed and died, he had received two large doses of erythromycin. The total length of illness was nine hours.

At postmortem examination the patient was well nourished with a membranous tonsillitis, laryngotracheitis, and bronchopneumonia. There was a cervical lymphadenitis, and a moderate splenomegaly with a soft pinkish-grey pulp.

Swabs of the membrane grew $C$. diphtheriae mitis. Histology revealed similar findings in the tonsils, respiratory tract, and cervical lymph nodes as in case 3.

\section{Case 5}

This was the only death during the second outbreak. He was a severely subnormal epileptic patient of 23 years, doubly incontinent, untidy, and destructive. He had a tendency to injure himself by banging his head against various objects. He spoke a few words and could just manage to feed himself. There was a past history of numerous skin infections treated by antibiotics and he was heavily sedated for epilepsy. He was the only patient not immunized against diphtheria after the first outbreak. His illness commenced on 23 November (five months after the last fatal case) at about midday with a temperature of $101^{\circ} \mathrm{F}\left(38.3^{\circ} \mathrm{C}\right)$ with severe pharyngitis and obvious clinical upper respiratory tract obstruction. The throat was difficult to see clearly but the left tonsil was noted to be enlarged with a covering of necrotic exudate; the right tonsil was similar but to a lesser degree. The cervical lymph nodes were slightly enlarged. Auscultation of the chest revealed poor air entry and generalized crepitations. Benzylpenicillin was immediately given and later he received 5000 units of diphtheria antitoxin. Although the patient's condition at $9.30 \mathrm{pm}$ gave no rise for concern, he collapsed and died suddenly at $4.20 \mathrm{am}$. The total length of illness was $16 \frac{1}{2}$ hours.

At postmortem examination the patient was a thin young male with an adherent membrane from the nasopharynx down the larynx and trachea and continuing as far as the medium-sized bronchi. The lungs showed severe congestion and oedema with patchy irregular areas of bronchopneumonia. The cervical lymph nodes were haemorrhagic and oedematous. There was generalized visceral congestion and in the brain a dilated right lateral ventricle.

\section{SIMILARITY OF NECROPSY FINDINGS}

In the four postmortem examinations on the fatal diphtheria cases the findings were strikingly similar. In the nasopharynx and tonsil the diphtheritic membrane consisted of two elements, namely, a superficial thick, fibrino-purulent exudate and inflamed and necrotic underlying tissue. This was particularly striking in the tonsil where the surface exudate followed exactly the contours of the tonsillar crypts and merged with the underlying inflamed and necrotic lymphoid tissue. The squamous epithelium of the tonsil had disappeared. The deeper tonsillar lymphoid tissue showed intense inflammation with an outpouring of fibrin continuous with that on the surface, and many of the germinal centres showed either necrosis or marked degenerative changes. It is this binding together of the surface exdudate and necrotic underlying tissue by fibrin on the tonsil that presumably makes the detachment of the membrane difficult during life whereas the membrane formed in the larynx, trachea, and bronchi involving a single layer of epithelium is easily detached. In fact all were cases of pharyngo-laryngo-tracheobronchial diphtheria with the formation of pseudocasts of the trachea precisely similar to that depicted in 'A treatise on pathological anatomy' by W. E. Horner, published in 1829 (fig 10). The fact that the diphtheritic membrane could take this form, coupled with the lack of initial corroborative bacteriological evidence, led to some delay in establishing the identity of the disease.

\section{Bacteriology}

Although other swabs were taken the only isolations were from the noses and throats of cases or carriers. The organisms isolated appeared to be similar to and typical of $C$. diphtheriae mitis, the only variation being that five strains were non-toxigenic on Elek plates and avirulent for guinea pigs. 


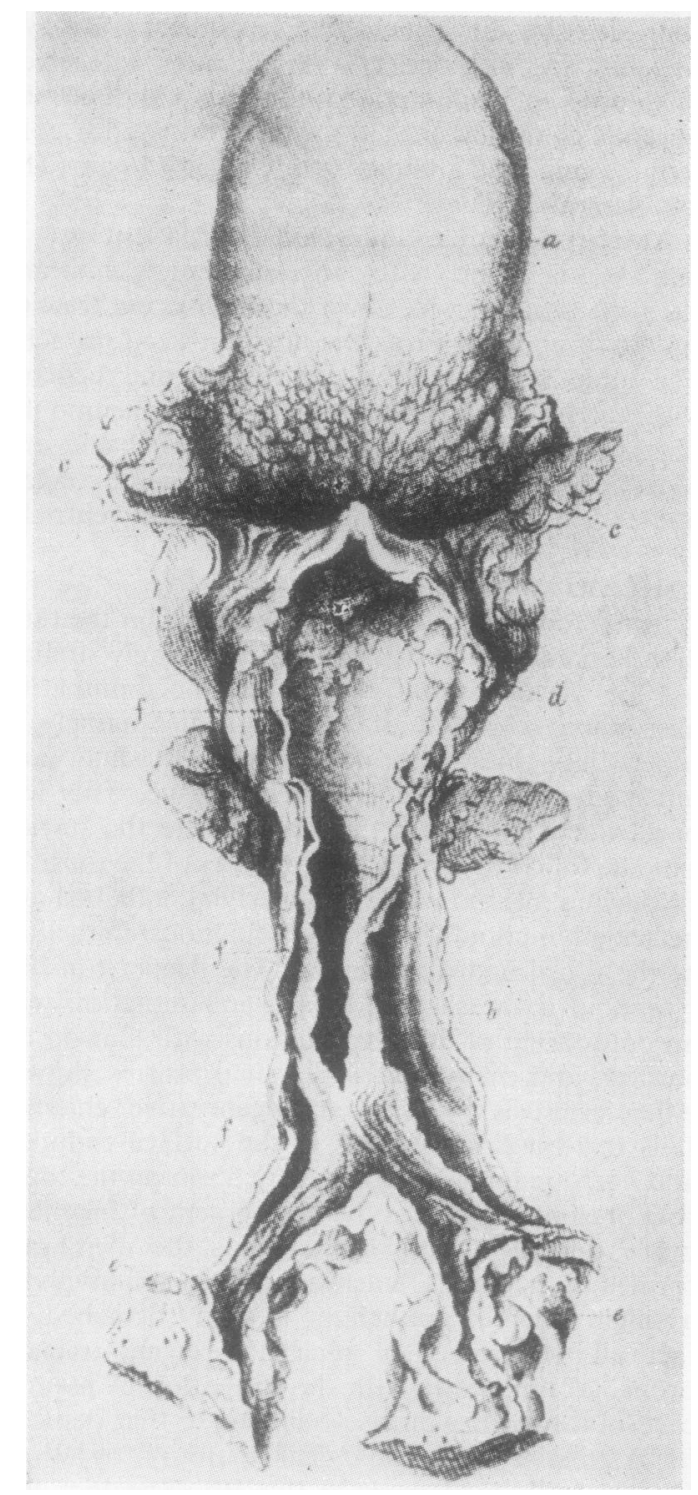

Fig 10 From a drawing of a diphtheritic cast (plate IV) in A treatise on pathological anatomy 1829 by $W . E$. Horner.

The organism grew well on nutrient agar, better on horse blood agar with a vague general haemolysis, and profusely with raised, discrete, moist almost translucent colonies on Loeffler's serum medium. The growth on Downie's tellurite medium was quite characteristic with colonies about $1 \mathrm{~mm}$ diameter in 24 hours and $2 \mathrm{~mm}$ diameter in 48 hours. The colonies were raised, slightly pointed, and darker centrally and lighter at the periphery. They were not jet black but like very dark pewter. The colonies were not detachable as a whole but broke when touched with a loop. They were butyrous in consistency and emulsified readily.

On microscopic examination the 'typical KLB morphology' was present. The organisms were pleomorphic but mainly long, thin, and irregular with many metachromatic granules and areas of $\vec{\circ}$ intense and poor staining. They were arranged irregularly. They were Gram-positive but the morphology was better seen by using Loeffler's, Neisser's, or Albert's stain. As usual the most typical appearance was seen in films from Loeffier's medium.

The organism was catalase + , oxidase - , and urease-; it did not liquify gelatin. It fermented glucose, maltose, galactose, and dextrin but not sucrose and starch. It was sensitive to sulphonamide, penicillin, ampicillin, cloxacillin, streptomycin, fucidic acid, erythromycin, and tetracycline.

At first it was thought to be non-toxigenic and avirulent but later tests gave uniform and clear positive results with Elek's plates except of course for the non-toxigenic strains. The serum used appeared to be important in this test and we obtained our best results with unheated horse serum no. 3 (Wellcome Reagents Ltd, Beckenham, Kent). Controls must always be used and the test confirmed by guinea pig inoculation, which is the final criterion. Even this test can be difficult as the early results with intradermal testing were equivocal and it is probably best to inject a bacterial suspension subcutaneously into immune and non-immune animals and note if the non-immune animal dies within 48 hours with typical postmortem examination findings.

\section{Comment}

The origin of the outbreak is unknown. No carrier is known to have introduced the organism. In 1951 Freeman and later other workers showed that an avirulent strain can, by the action of a suitable bacteriophage, be converted into a virulent strain and it is only speculation that such a change occurred in the outbreaks described here in a non-toxigenic strain by the introduction of an appropriate bacteriophage. Perhaps it is significant that five non-toxigenic strains were isolated in these outbreaks when they are extremely rare in the normal population.

Another point for which there appears to be no explanation is the delay of three weeks between the first and second cases which occurred in different villas. Nor is it known why the women's and the children's villas escaped. 
The delay of five months between the outbreaks may be explained by three factors - the missing of a carrier after the first outbreak, by the penicillin treatment, and by the immunization programme carried out at that time. It is extremely easy to miss a carrier in such patients. The difficulties of taking swabs are immense as the patients often cannot understand or cooperate and may be actively and violently hostile. Frequently it is doubtful if a valid swab has been taken. Penicillin treatment is not the best for diphtheria as it is liable to cause diphtheria bacilli to disappear temporarily from the accessible throat surfaces to become recolonized later, possibly from the tonsillar crypts. Erythromycin would probably have been more effective. The immunization programme probably allowed the spread of the organisms to many people during this danger period and only came to light when the organism reached the one unimmunized patient from the first outbreak.

The deaths of three patients in contiguous beds have not been satisfactorily explained.

The patients and staff were immunized after the first outbreak with two doses of TAF and the Schick testing showed that while there was a fair response, complete immunization of the village was not achieved. It may be that better results would have been obtained by PTAP or PTAH which has been given to those still Schick positive after TAF immunization.

Apart from the early cases, carriers and patients were treated with erythromycin with apparently satisfactory results. One nurse carried a nontoxigenic strain until March 1971.

The whole village population was swabbed once a month for six months but this heavy task was worthwhile as two further carriers were identified. Wright in 1941 showed that in $2.5 \%$ of patients three successive weekly negative swabs were followed by a positive and our results of the identification of the two extra carriers would agree with his findings. No further cases have occurred in the past 24 months.

There is no evidence that the organism was any different from the organism seen years ago but it would appear that with its recent rarity its presence can be missed as in the first case here. It was diag- nosed as acute pharyngolaryngo-tracheo-bronchitis and the negative swabs at postmortem examination may have been due to the previous penicillin and streptomycin given or the natural death of the organism two days after the death of the host.

It would seem that with three major outbreaks at Colchester, Manchester, and London in 1970 more cases of diphtheria will be seen in the future.

From our experience we would like to stress two final points. First, it must be realized that diphtheria is not a disease of the past. It must always beseriously considered in the differential diagnosis of every membranous sore throat, tonsillitis, and pharyngitis. If it is diagnosed clinically nose and throat swabs should be taken and immediate treatment with antitoxin and antibiotics undertaken, without waiting for the bacteriological results. Nor should one be deterred by negative results in direct smears, Elek plates, or toxigenicity tests from making a clinical diagnosis.

Secondly, with the decline in the incidence of disease, there has been a decline in vigilance against it. This must be maintained and the diphtheria immunization programme strengthened.

We wish to express our thanks to the medical and nursing staff of the Royal Eastern Counties Hospital, in particular Mr R. Gray, former chief male nurse at Turner village. Our thanks are due to $\mathrm{Mr}$ C. D. Lee and Mr L. S. Smith of the RECH Laboratory, who bore the brunt of the laboratory work involved, to $\mathrm{Mr} \mathrm{H}$. Amey and Mr P. Doughty of the Colchester and District Laboratories. We also wish to thank Dr R. Pilsworth and his staff at the Chelmsford PHLS Laboratory and Dr W. H. H. Jebb and his staff at the Diphtheria Reference Laboratory, Oxford. Finally, we are grateful to Professor I. Friedmann and Mr R. S. F. Cathmoir for the photographs.

\section{References}

Horner, W. E. (1829). A Treatise on Pathological Anatomy. Carey, Philadelphia

Freeman, V. J. (1951). Studies on the virulence of bacteriophageinfected strains of Corynebacterium diphtheriae. J. Bact., 61, 675-688.

Wright, H. D. (1941). The disappearance of $C$. diphtheriae from diphtheria patients. J. Path. Bact., 52, 129-132. 